George V. Guibas ${ }^{1}$, Yannis Manios ${ }^{2}$, George Moschonis ${ }^{2}$, Paraskevi Xepapadaki ${ }^{1}$, Eirini Roumpedaki ${ }^{1}$,

Christina-Paulina Lambrinou ${ }^{2}$ and Nikolaos G. Papadopoulos ${ }^{1}$

${ }^{1}$ Allergy Dept, 2nd Pediatric Clinic, University of Athens, Athens, and ${ }^{2}$ Dept of Nutrition and Dietetics, Harokopio

University of Athens, Athens, Greece.

Correspondence: N. G. Papadopoulos, 41 Fidippidou Street, Athens, 115 27, Greece. E-mail: ngp@allergy.gr

Received: July 262013 | Accepted after revision: Dec 192013 | First published online: Feb 202014

Conflict of interest: Disclosures can be found alongside the online version of this article at www.erj.ersjournals.com

\title{
References
}

1 Pike KC, Crozier SR, Lucas JS, et al. Patterns of fetal and infant growth are related to atopy and wheezing disorders at age 3 years. Thorax 2010; 65: 1099-1106.

2 Paul IM, Camera L, Zeiger RS, et al. Relationship between infant weight gain and later asthma. Pediatr Allergy Immunol 2010; 21: 82-89.

3 Taveras EM, Rifas-Shiman SL, Camargo CA Jr, et al. Higher adiposity in infancy associated with recurrent wheeze in a prospective cohort of children. J Allergy Clin Immunol 2008; 121: 1161-1166.

4 Flexeder C, Thiering E, Brüske I, et al. Growth velocity during infancy and onset of asthma in school-aged children. Allergy 2012; 67: 257-264.

5 Rona RJ, Smeeton NC, Bustos P, et al. The early origins hypothesis with an emphasis on growth rate in the first year of life and asthma: a prospective study in Chile. Thorax 2005; 60: 549-554.

6 Van der Gugten AC, Koopman M, Evelein AM, et al. Rapid early weight gain is associated with wheeze and reduced lung function in childhood. Eur Respir J 2012; 39: 403-410.

7 Manios Y. Design and descriptive results of the "Growth, Exercise and Nutrition Epidemiological Study In preSchoolers": the GENESIS study. BMC Public Health 2006; 6: 32.

8 Moschonis G, Tanagra S, Vandorou A, et al. Social, economic and demographic correlates of overweight and obesity in primary-school children: preliminary data from the Healthy Growth Study. Public Health Nutr 2010; 13: $1693-1700$.

9 National Statistical Service of Greece Population and Housing Census 2001. www.unece.org Date last updated: February 2003. Date last accessed: February 2014.

10 Sonnenschein-van der Voort AM, Jaddoe VW, Raat H, et al. Fetal and infant growth and asthma symptoms in preschool children: the Generation R Study. Am J Respir Crit Care Med 2012; 185: 731-737.

11 Rzehak P, Wijga AH, Keil T, et al. Body mass index trajectory classes and incident asthma in childhood: results from 8 European Birth Cohorts - a Global Allergy and Asthma European Network initiative. J Allergy Clin Immunol 2013; 131: 1528-1536.

\section{Replacing smear microscopy for the diagnosis of tuberculosis: what is the market potential?}

\section{To the Editor:}

Sputum smear microscopy (SSM) has been the cornerstone of tuberculosis (TB) diagnosis, and is mainly performed in peripheral microscopy centres attached to primary health centres where TB therapy can be administered. Although SSM is inexpensive and easy to perform with a limited infrastructure, the shortcomings are its relatively low sensitivity and its inability to detect drug-resistance. Thus, there is a need for a more sensitive technology that can replace microscopy $[1,2]$.

Several next-generation molecular diagnostics are under development with the specific intention of use in microscopy centres [3-5]. In a recent survey of 22 high-burden countries (HBCs), we showed that the conditions, equipment and expertise present in microscopy centres are challenging and need to be considered by product developers [6]. While the Xpert MTB/RIF (Cepheid Inc., Sunnyvale, CA, USA) assay is accurate, endorsed by the World Health Organization and is being implemented in many countries, it was not designed for use in peripheral microscopy centres $[7,8]$. To assist product developers working on tests for use in microscopy centres, we have outlined the desirable test characteristics [1]. 
For companies to take on the challenge and invest in new diagnostics, an understanding of the potential market size is paramount [9]. A 2006 global TB diagnostics market analysis predicted that a smear replacement test applied at the level of peripheral clinics and microscopy centres would have a potential market size of 36.6 million tests per year in the 22 HBCs in 2020, assuming it would diagnose pulmonary, extrapulmonary and paediatric TB [10]. However, current and next-generation molecular tests are reliant on sputum specimens and are unlikely to accurately diagnose all forms of TB [5].

To provide a snapshot of the current market, we surveyed experts in each of the 22 TB HBCs, in order to estimate the current SSM market and its potential replacement market for the diagnosis of pulmonary TB. The survey, sent via email to staff working in National Tuberculosis Programmes (NTP) ( $\mathrm{n}=17$ countries) or TB consultants working closely with NTPs ( $n=5$ countries), included questions on the number of smear microscopy centres, the annual number of smears carried out in the public (NTP) sector (where possible, stratified by initial diagnosis and treatment monitoring), the national recommendation on number of smears, and smear volumes in the private sector. If the annual smear volume of the country seemed unrealistically high or low ( $>35$ or $<2$ smears per notified TB case, respectively), respondents were contacted again for verification.

Respondents were asked to provide a cost value for one smear in their country. However, this resulted in heterogeneous cost estimates because of variations in how costs were computed. Therefore, we multiplied test volumes by the median unit cost (and interquartile range (IQR)) for one smear obtained from a recent systematic review of SSM from 23 studies in 11 countries [11]. When converted to 2012 US\$, the unit cost for a smear was US\$1.77 (IQR US\$1.28-2.69) and included various components (e.g. material, labour, equipment and overheads) although components differed across studies.

We received a response for all $22 \mathrm{HBCs}$. As shown in table 1, the $22 \mathrm{HBCs}$ performed a total of 77.6 million sputum smears annually at a value of US $\$ 137$ million in 42827 microscopy centres. Of these, $61 \%$ were performed in the BRICS countries (Brazil, Russian Federation, India, China and South Africa). Most countries (19 out of 22) provided data for 2012, while the rest did so for 2011.

In the majority (13 out of 22) of HBCs, the NTP policy recommended testing three sputum samples for initial diagnosis of pulmonary TB, while the rest had a policy of two smears. 11 (50\%) countries disaggregated smear volumes into those performed for initial diagnosis and those for treatment monitoring. On average, $79 \%$ of the smears were performed for initial diagnosis (range 65-94\%). Since there was not much difference between countries that had a two- or three-smear policy in place, we extrapolated this percentage to all countries.

Using the data above and assumptions, we computed the smear replacement market by: 1) focusing on only initial diagnosis; 2) assuming that only one molecular test is necessary to replace two or three smears; and 3 ) assuming that the hypothetical unit cost (consumables only) of the replacement test would be US $\$ 5$.

The annual SSM market size for the initial diagnosis of TB in the 22 HBCs was estimated to consist of 61.7 million smears (79\% of 77.6 million) at an expenditure of US\$109 million (range based on IQR of smear costs US\$79-166 million). After accounting for the assumptions about single replacement tests at a cost of US $\$ 5$, we estimated the potential market size for a replacement test to be 30.8 million tests, with a potential market value of US $\$ 154$ million per year.

Our analysis has limitations. We focused on the public sector, while several HBCs (notably India, Pakistan, Bangladesh, Indonesia, Cambodia, Nigeria, Uganda and the Philippines) are known to have a sizable and even dominant private sector [13]. Although countries were asked to provide smear volumes for the private sector, few were able to do so. Therefore, private sector data were not included and the actual market potential may in fact be higher than our estimate. Likewise, by assuming that a smear replacement test would be performed once and would not be used for treatment monitoring or for extrapulmonary TB, we may have underestimated the true potential market. Furthermore, our results relied on the accuracy of existing NTP data which may have missed some smears carried out in the public sector that were not reported to the NTP.

We may have also underestimated the smear market value because we used the same smear cost for all countries while the actual costs varied considerably. In particular, in BRICS, where over half of the smears were performed, the costs for a smear may be higher than our uniform estimate. However, the potential market size may not be fully addressable for a given replacement test. The addressable market will depend on the technology, pricing structures, ability to penetrate the private market, donor subsidies and initiatives, and other competing options, including the market share achieved by the ongoing implementation of Xpert $\mathrm{MTB} / \mathrm{RIF}$ in some countries. 


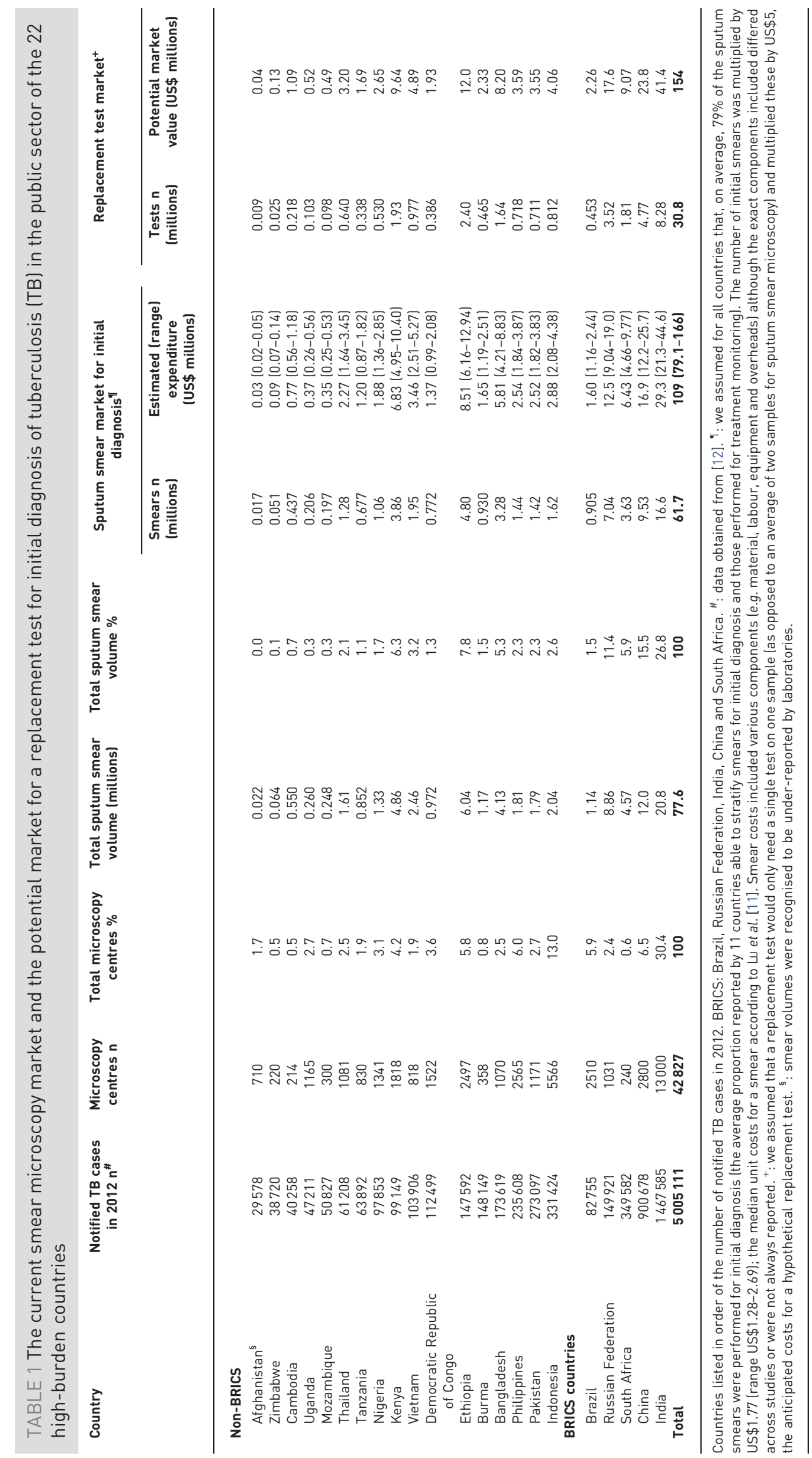


For some HBCs, our hypothetical price of US $\$ 5$ for a new molecular test might be too expensive for smear replacement, given limited budgets. For example, if the Xpert MTB/RIF assay (cartridge price of US\$9.98) were to be used for all people with presumed $\mathrm{TB}$, the cost will exceed $80 \%$ of the total $\mathrm{TB}$ spending in countries such as India, Bangladesh, Indonesia and Pakistan [14]. For these countries a new molecular test might be applied as a confirmatory test after a positive triage test. So, the potential market for such a confirmatory test would be lower than a smear replacement test.

In conclusion, we showed that in the $22 \mathrm{HBCs}$, over 77 million smears are performed annually. Over $60 \%$ are carried out in the BRICS, which clearly represent an important market for new technologies. We estimated that a more accurate smear replacement test which would test the same target population in the 22 HBCs would have a market size of at least 30.8 million tests and a potential market value of US\$154 million per year. These data should be of value to product developers, donors and investors.

0 @ERSpublications

The estimated market for a sputum smear microscopy replacement test in 22 high-burden countries is $\$ 154$ million per year http://ow.ly/sTXNc

Sandra V. Kik ${ }^{1,2}$, Claudia M. Denkinger ${ }^{1,2,3}$, Pamela Chedore ${ }^{1,2}$ and Madhukar Pai ${ }^{1,2}$

${ }^{1}$ McGill International TB Centre, McGill University, Montreal, and ${ }^{2}$ Dept of Epidemiology and Biostatistics, McGill University, Montreal, QC, Canada. ${ }^{3}$ Division of Infectious Disease, Beth Israel Deaconess Medical Center, Boston, MA, USA.

Correspondence: M. Pai, Dept of Epidemiology and Biostatistics, McGill University, 1020 Pine Ave West, Montreal, QC H3A 1A2, Canada. E-mail: Madhukar.pai@mcgill.ca

Received: Dec 122013 | Accepted after revision: Jan 082014 | First published online: Feb 132014

Acknowledgements: We are grateful to all the survey respondents for their time and support. We would like to thank C. Jefferson, independent consultant (currently consulting for UNITAID, Geneva, Switzerland), for providing comments on the draft manuscript.

Support statement: This work was supported by the Bill and Melinda Gates Foundation (grant OPP1061487). M. Pai is supported by the Fonds de recherche du Québec - Santé (FRQS; Montreal, Canada). C.M. Denkinger is supported by a Richard Tomlinson Fellowship at McGill University (Montreal, Canada) and a fellowship of the Burroughs-Wellcome Fund from the American Society of Tropical Medicine and Hygiene (Deerfield, IL, USA).

Conflict of interest: Disclosures can be found alongside the online version of this article at www.erj.ersjournals.com

\section{References}

1 Denkinger CM, Kik SV, Pai M. Robust, reliable and resilient: designing molecular tuberculosis tests for microscopy centers in developing countries. Expert Rev Mol Diagn 2013; 13: 763-776.

2 Pai NP, Vadnais C, Denkinger C, et al. Point-of-care testing for infectious diseases: diversity, complexity, and barriers in low- and middle-income countries. PLoS Med 2012; 9: e1001306.

3 Lawn SD, Mwaba P, Bates M, et al. Advances in tuberculosis diagnostics: the Xpert MTB/RIF assay and future prospects for a point-of-care test. Lancet Infect Dis 2013; 13: 349-361.

4 Niemz A, Boyle DS. Nucleic acid testing for tuberculosis at the point-of-care in high-burden countries. Expert Rev Mol Diagn 2012; 12: 687-701.

UNITAID. Tuberculosis: Diagnostics Technology Landscape. Geneva, WHO, 2013.

6 Denkinger CM, Nicolau I, Ramsay A, et al. Are peripheral microscopy centres ready for next generation molecular tuberculosis diagnostics? Eur Respir J 2013; 42: 544-547.

7 Weyer K, Mirzayev F, Migliori GB, et al. Rapid molecular TB diagnosis: evidence, policy making and global implementation of Xpert MTB/RIF. Eur Respir J 2013; 42: 252-271.

8 World Health Organization. Automated real-time nucleic acid amplification technology for rapid and simultaneous detection of tuberculosis and rifampicin resistance: Xpert MTB/RIF system for the diagnosis of pulmonary and extrapulmonary TB in adults and children. Policy Update. Geneva, WHO, 2013.

9 Pai M. Diagnostics for tuberculosis: what test developers want to know. Expert Rev Mol Diagn 2013; 13: 311-314.

10 World Health Organization/Special Programme for Research \& Training in Tropical Diseases/Foundation for Innovative New Diagnostics. Diagnostics for tuberculosis. Global demand and market potential. Geneva, WHO, 2006.

11 Lu C, Liu Q, Sarma A, et al. A systematic review of reported cost for smear and culture tests during multidrugresistant tuberculosis treatment. PLoS One 2013; 8: e56074.

12 World Health Organization. Global Tuberculosis Report 2013. Geneva, WHO, 2013.

13 Wells WA, Ge CF, Patel N, et al. Size and usage patterns of private TB drug markets in the high burden countries. PLoS One 2011; 6: e18964.

14 Pantoja A, Fitzpatrick C, Vassall A, et al. Xpert MTB/RIF for diagnosis of tuberculosis and drug-resistant tuberculosis: a cost and affordability analysis. Eur Respir J 2013; 42: 708-720. 